\title{
Assessing Causes and Impacts of Traffic Congestion in Khartoum, Sudan
}

\author{
Magdi M. E. Zumrawi ${ }^{1, *}$ \\ 1 Faculty of Engineering, University of Khartoum, Khartoum, Sudan \\ * Corresponding author: Magdi M. E. Zumrawi (e-mail: magdi.zumrawi@yahoo.com).
}

Article history: Received 08 March 2020, Received in revised form 4 November 2020, Accepted 11 November 2020

\begin{abstract}
This paper discusses a serious problem of traffic congestion in Khartoum in order to identify its causes and impacts on society and economy. The literature relating to the problem of traffic congestion were intensively reviewed. The research methodology have been adopted includes questionnaire, interviews and site visits. The data collected were statistically analyzed. The results indicated that the traffic congestion contributing to insufficient road capacity, lack of public transport and parking problems. It was found that traffic congestion has adverse effects such as time consuming, decrease in productivity and fuel consumption. Finally, some major measures were provided to reduce traffic congestion in Khartoum by expansion of roads, managing parking and adopting Bus Rapid Transit (BRT) system.
\end{abstract}

Keywords: Causes, Impacts, Parking, Traffic congestion.

\section{INTRODUCTION}

The traffic condition in third world countries like Sudan poses serious problems. Demand for road travel continues to grow as population increases. In many countries, the automobile has become a predominant way of traveling. Traffic congestion on roads is created due to high number of vehicles and increased number of pedestrians.

Recently, the traffic congestion has reached an alarming rate in Khartoum, capital of Sudan. The increasing population along with the rapid growth of privacy car become a challenge in Khartoum. The overcrowding of vehicles on the roads leads to a number of problems include travel delay, wastage of fuel and increasing air pollution, stressed and discomfort of passengers and drivers. Congestion increases the tendency of collision which may lead to series of injuries and fatality. Therefore how to solve traffic congestion becomes an essential and urgent issue for many countries. In Sudan, limited progress has been achieved in managing traffic congestion. This study aimed to identify the causes of traffic jam and uses this data to come up with suggestions and recommendations to improve the current traffic situation.

\section{LITERATURE REVIEW}

\section{A. Background}

Traffic congestion is a situation where more people try to use a given transportation facility during a specific period of time with delay or inconvenience. Traffic congestion which can lengthen travel time, increase energy consumption, cause environmental pollution and traffic accidents. Road congestion in cities is mostly the result of economic development that encourage individuals to work and live closer. The remarkable increase in the number of vehicles on roads as a result of rapid urbanization has led to a rise in traffic volume, thus causing roads to be congested in cities [1].

The road traffic congestion is a matter of 
concern for many researchers and transportation professionals. According to Zhang [2], inefficient public transport services for people in China as well as the inverse relationship exists between the number of vehicles and the road capacity result in traffic jam. Additionally, Reunion Island, where the only means of travel is by road, experienced an increase of $126 \%$ in the number of private vehicles in the period from 1990 to 2010 . This is because people homes and the work places are situated at a distance, and businesses are concentrated in only a few coastal cities. Furthermore, in a study conducted by Rao and Rao [3], it was revealed that the problem of traffic congestion is prevalent in India because most cities suffer from moderate to severe congestion. Traffic congestion in India occurs mainly because of the poor road conditions, varying road way features, poor lane discipline, inappropriate bus-stop location and design, diversity of traffic, and unrestrained on-street parking.

\section{B. Causes of Traffic Congestion}

Researchers and traffic experts in many countries reported various reasons for traffic congestion such as population growth, insufficient road capacity, bottleneck traffic, lack of public transport, parking problems and other factors contribute in traffic delay [4-21].

According to the study conducted by Raheem et al. [4], as the population of a country grows, the demand for road travel also increases. They found that the growth in population has not been complemented by the construction of new roads, thus causing roads to be congested. Moreover, increasing of population living in urban areas and a number of vehicles per household lead to increase in the demand for roads [5].

Thakur and Singh [6] found that more cars on the roads are one of the reasons which leads to increase in congestion. As the financial growth of citizen's increase with increase in population, the demand for personal vehicles for daily commute also rises among citizens. Hence the increase in number of vehicles and increase in chances of congestion are directly related. As stated in the TAC [7], the excessive number of vehicles on the roads is one of the primary reasons why traffic congestion arises.
As reported by US Department of Transportation [5], road congestion is caused either by decreased capacity of the road or increased demand for transportation. The biggest contributors to this are bottlenecks or narrowed roads that lead to increased congestion when demand for traffic is higher than supply. Based on road structure, lane reduction bottleneck occurs when the number of lanes is reduced causing two or more lanes to merge into one lead to delays, thus causing traffic congestion.

Jain et al. [8] studied the problem of road congestion in developing countries and found that congestion can occur due to the narrow and poorly constructed roads and streets that are ineffective in handling various vehicle types. This results in the inability to effectively manage traffic, creating bottlenecks that last for extended periods.

As in the study by Atomode [9], urban road intersections are bottlenecks that easily become the worst hit of traffic delay. This is because, at intersections, vehicular flows from several different approach making either left-turn, through and right-turn movements seek to occupy the same physical space at the same time. In addition to vehicular flows, there are also pedestrians who need space to pass the streets thereby making the situation even worse.

In their study, Harriet et al. [10] revealed that the ineffectiveness of public transport to offer services efficiently gives rise to traffic congestion, which in turn has critical repercussions on the socio-economic activities of a country. Moreover, Kiunsi [11] reported that because of weak public transport, people will be encouraged to use their cars instead, thus adding to the demand for roads. Moreover, inadequate parking spaces, poor urban planning, economic growth, signal failure, and other important factors contribute in increasing demand for road usage.

Doçi and Bajraktari [12] stated that one of traffic delay factor can be considered, the presence of heavy transport vehicles. Due to the number of stops that buses have to make throughout their daily travel, and the majority of the time there are no designated lanes for buses, they end up unintentionally delaying vehicles behind them, thereby adding to traffic congestion. 
Many other factors contributing to traffic congestion include accidents, harsh weather conditions, and road maintenance or construction works. An accident can cause a road blockage or slow down traffic flow as drivers try to understand what is happening. Likewise, bad weather conditions can cause drivers to slow down as they worry for their safety. Also, road maintenance or construction works can cause reduction of lanes thereby forcing drivers to crowd the open lanes. Consequently, traffic congestion can be highly increased by these factors, but because of their randomness, not much can be done to prevent incidents [13].

\section{Impacts of Traffic congestion}

Traffic congestion has many negative impacts ranging from economic loss to adverse environmental and social impacts. The effects of long travels and traffic congestion include tendencies for drivers to become impatient that if not properly addressed will lead to resentment and anger and may cause fighting and crimes. The effect of stress will directly affect health related problems such as lower fitness levels, increase blood pressures as well as higher chronic stress. When the stress level is going high, it would trigger into more health problems. Another negative effect of heavy traffic is air pollution. Drivers who are exposed to air pollution will likely experienced health risk particularly lung problem [14].

According to the WHO [15], the air population has killed 3.2 million lives worldwide yearly that can be directly attributed to traffic related incident. With increased traffic pollutant, it can cause incidents for heart attacks, increase blood pressures, and other related problem. Furthermore, long traffic can also attribute to lack of sleep. Especially traffics during midnights can deprive drivers and commuters of sleep that change their behaviors and moods. Sleep deprivation is known to contribute negative effects on performance, attention and long-term memory. Also, it can cause anxiety, frustration, impulsive behaviors, and lower immunity.

Because the roads are free of charge, there will be no financial incentive that would stop drivers from overusing the roads until the point where the road begins to collapse through continuous congestion [16]. By doing so, each driver incurs a private and public cost when they drive. The private cost includes the journey time and fuel used, whereas the public cost includes the cost imposed to the community in the form of noise, accident risk, fumes, etc. [17]. Both of these costs will increase with the increase of traffic congestion. Drivers waste more time and fuel if they are stuck in a traffic jam. The wasted time is the time that could be used productively and there is an economic cost attached to it which, although difficult to measure, can be significant [18].

Traffic congestion forces vehicles to stay longer time in roads, thereby increasing the emission of air pollutants. According to Robinson [18], the emission of Carbon Monoxides and Hydrocarbons is higher at speeds less than 20 $\mathrm{km} / \mathrm{h}$. These tail-pipe emissions harm the environment thus leading to health problems. According to Currie and Walker [19], the main contributors to air pollution are motor vehicles. Half of the carbon monoxide (CO), one third of Nitrogen Dioxide (NO2), and 29\% of hydrocarbons $(\mathrm{HC})$ in the atmosphere are released from cars only. Carbon monoxide (CO) reduces the oxygen in blood thereby reducing the accessibility of oxygen for organs. This poses a health risk, particularly to those with heart problems. Nitrogen oxides (NO) stimulate respiratory problems and increased sensitivity to allergens. Nitrogen oxides also contribute in formation of ground-level ozone and acid rain which can damage vegetation. Hydrocarbons (HC) can cause respiratory problems as well. They participate in formation of ground-level ozone too.

Besides economic and environmental harms, traffic congestion can also influence the social and psychological being of the citizens. As Robinson [18] stated that nobody enjoys being caught in a traffic jam; it is likely to make the blood pressure jump a few notches and induce the unlikeliest people to use language that would make a sailor blush. That is, road rage or a similar emotional state would be among outcomes of congestion. 
In addition, the noise that is caused by heavy traffic streams which reaches $90 \mathrm{db}$ creates an undesirable environment [18]. Furthermore, when the line of traffic becomes large and the waiting time becomes intolerable for someone, these individuals will seek alternative ways to avoid traffic congestion. By doing so, they will cause local residents great distress [18].

\section{MethodOLOGY}

The research methodology used to collect relevant information regarding traffic congestion in Khartoum. These methods were designed to identify the causes of traffic congestion and to evaluate the economic, environmental and social impacts of this phenomenon.

\section{A. Study area}

Khartoum is the capital of Sudan with a population of 12 million as of 2008. It is located where the Blue Nile and White Nile Rivers merge. The capital is actually made out of three distinct cities (Khartoum, Khartoum North or Bahri, and Omdurman) which are divided by the Nile and its two branches. As shown in Fig. 1, the Blue Nile flows between Khartoum and Bahri, the White Nile between Khartoum and Omdurman, and the merged Nile between Bahri and Omdurman.

Khartoum proper is the seat of the Sudanese government and is the largest of the three cities. The older part of the city lies beside the White Nile while the newer parts spread out to the south. This study focuses on Khartoum city, an area that is experiencing severe congestion, attributed mostly to the large number of cars on the road entering Khartoum every day.

The current modes of commuting in Khartoum are private car, bus (with capacity of 30-40 passengers), minibus (with capacity of 14-20 passengers), shared taxi (known locally as service, with capacity of 4 passengers), private taxi, bike, and motorcycle. Most of the public transportation modes are operated by the private sector in an unregulated manner except the buses belongs to Khartoum Public Transport Company. The bus and minibus fares are the standard fares in operation. Taxi-service fare is based on the service fare (which is decided based on trip distance). There are no tolls in Khartoum and car parking is free of charge.

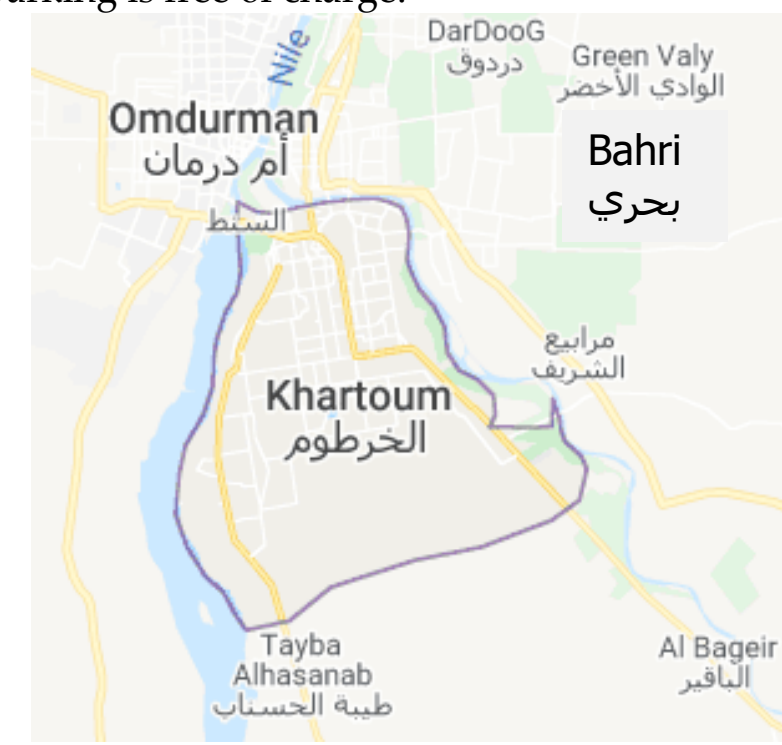

Fig. 1. Khartoum study area map

\section{B. Research Methods}

Questionnaires, in-depth interviews and site observations were developed to collect primary data from the field. The questionnaire was divided into four sections. Section A focused on the demographic characteristics of respondents such as gender, the level of education, occupation, etc. Section B concerned with the factors cause traffic congestion while Section $C$ was on the impacts of traffic congestion in Khartoum. The final section, section D was on the possible measures needed to manage traffic congestion in Khartoum. 200 questionnaires were distributed among participants comprising experts in traffic and transportation planning as well as civil engineers, students and car owners/drivers, etc. Total 136 or $68 \%$ questionnaires were returned.

In-depth interviews were conducted to obtain information on causes and effects of traffic congestion and how it can be managed from the official representatives from the Ministries of Infrastructure of Khartoum state and Interior Affairs, in particular the top managers and traffic engineers. The study also made use of site observations. Site visits to the identified areas for traffic congestion in Khartoum were conducted on weekdays and holidays during the time from 6a.m. to 8p.m. The purpose of these visits was to quantify the traffic volume circulating on these 
sites. The data collection and site observations were used to study the traffic congestion in the study area. As secondary source of data, documents and reports collected from the ministries of interior affairs and infrastructure of Khartoum state.

\section{RESULTS AND DISCUSSION}

This section presents analysis, results and discussion of traffic congestion in Khartoum. The data collected were analysed using simple percentages and basic statistical tools to understand the trend of responses concerning traffic congestion problems in Khartoum. The results are presented in tables and figures.

\section{A. Modes of Transportation}

In order to understand the causes of traffic congestion, different means of transportation were available to respondents. As shown in Fig. 2, the survey results indicate that $36 \%$ use private cars, $26 \%$ use minibuses, $25 \%$ use taxes $(15 \%$ use shared taxies, $10 \%$ use private taxies), only $9 \%$ use buses and $4 \%$ use motorcycles and bikes. This result indicates that transportation in Khartoum is mostly done using private cars, mini buses and taxes. These have a tendency to increase congestion due to too many vehicles on the road. For instance 40 passengers in a single bus will translate to 10 to 20 vehicles on the road at the same period of time. Hence, the means available for transportation has a tendency to affect traffic congestion.

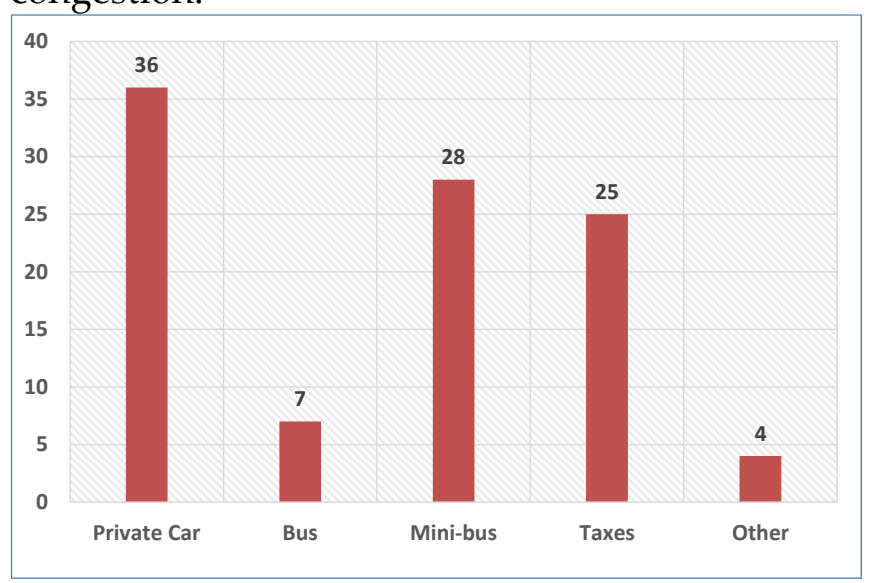

Fig. 2. Transportation modes used in Khartoum

According to Table 1, more than half of the respondents experienced the traffic congestion frequently while $47 \%$ experiencing it more frequently. The Table further shows that the majority of the respondents experienced the traffic jam duration is more than 15 minutes. More than $50 \%$ of the respondents waste 15 to 45 minutes in traffic jam while $45 \%$ spending more than 45 minutes. Therefore, the average delay in the traffic jam duration time is about 40 minutes.

\section{B.4.2 Time and Duration of traffic congestion}

The peak times of traffic congestion, as shown in Fig 3 and Table 1, occur from 7 a.m. to 9 a.m. $(47 \%)$ and then decreases significantly. It peaks again in afternoon from 2 p.m. to 4 p.m. (40\%) and again goes down. Since people always go to work in the morning at 7 to 9 a.m., therefore this is a peak time of traffic congestion. Afternoon when people go back home, the traffic jam increase again.

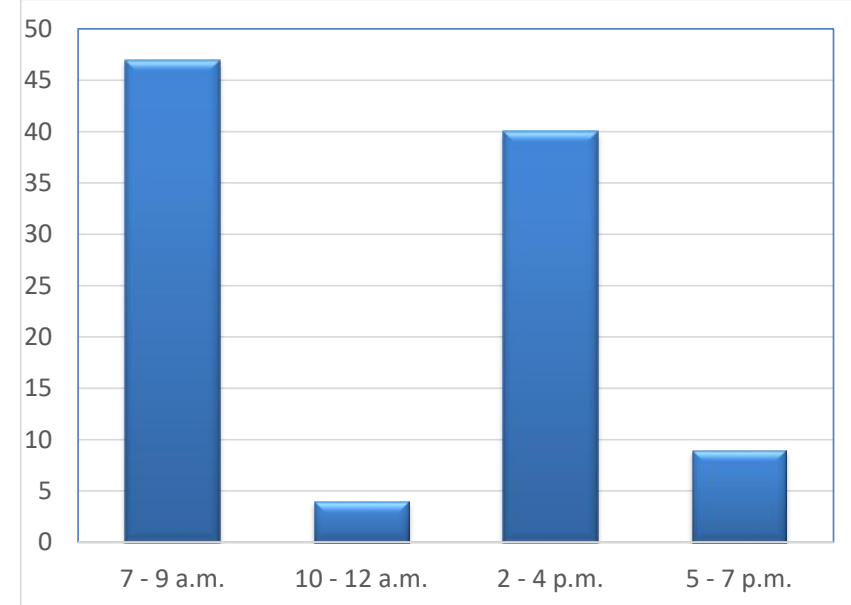

Fig. 3. Time of the day traffic congestion is experienced

TABLE I: TIME AND DURATION OF TRAffiC CONGESTION IN KHARTOUM

\begin{tabular}{lc}
\hline \hline Variable & Percentage \\
\hline Time of the day traffic congestion & 47 \\
7 - 9 a.m. & 4 \\
$10-12$ a.m. & 40 \\
$2-4$ p.m. & 9 \\
$5-7$ p.m. & \\
Frequency of traffic congestion & 45 \\
More frequently & 53 \\
Frequently & 2 \\
Seldom & 9 \\
$5-7$ p.m. & \\
Duration of traffic congestion & 2 \\
$<15$ min. & 21 \\
$15-30$ min. & 32 \\
$31-45$ min. & 23 \\
$46-60$ min. & 22 \\
$>60$ min. & \\
\hline \hline
\end{tabular}




\section{Causes of traffic congestion in Khartoum}

The study identified some factors that cause traffic jam in Khartoum as shown in Fig. 4, insufficient road capacity to accommodate the traffic flow represents (30\%), lack of public transportation $(28 \%)$, parking problems $(22 \%)$, and deterioration of some roads in Khartoum $(10 \%)$ are the major causes of traffic congestion in Khartoum. There are minor factors cause traffic congestion in Khartoum include poor timing of traffic signals $(5 \%)$ and special events and any other factors $(5 \%)$.

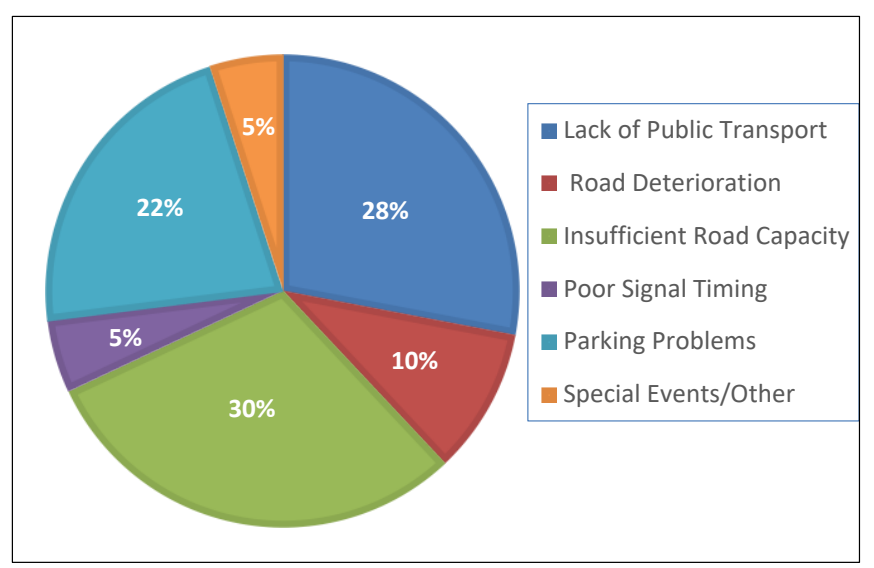

Fig. 4. Causes of traffic congestion in Khartoum

Based on the study results, the main factor causes road traffic congestion in Khartoum is that the roads are narrow and poorly built. As the city grows, no provision is made towards scaling road capacities, eventually resulting into several bottleneck roads, which remain congested for extended periods of time.

Another concerning issue is the lack of public transportation in Khartoum. According to the respondents of the study sample, the number of buses working in Khartoum is insufficient to serve all the citizens for their daily life. The deficiency of the public transport encourages people to use their own cars to travel in the city. Furthermore, insufficient parking spaces force the drivers to park their cars on the roads thereby adding to the demand for roads. Sometimes these cars are parked illegally, thus making it difficult for pedestrians and other cars to pass.

\section{Impacts of traffic congestion in Khartoum}

The adverse impacts of traffic congestion in Khartoum are shown in Fig 5, the majority of the respondents $(30 \%)$ noted that the traffic congestion is time consuming, (25\%) of the respondents perceived that traffic congestion decreases people productivity and (20\%) of the respondents showed fuel consumption as major negative effects of traffic congestion. In fact, the waste of time, decrease in productivity and fuel consumption as social effects cause a significant reduction in personal income. Fig 5 further shows traffic congestion causes stress and air pollution as $(15 \%)$ and $(10 \%)$ of the respondents declared respectively.

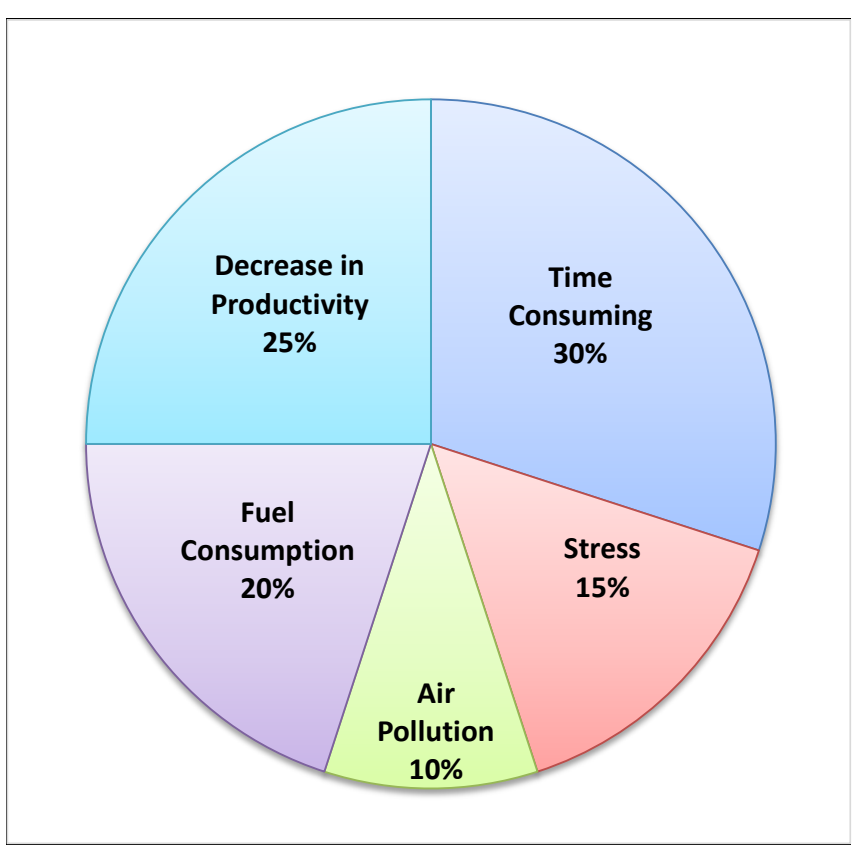

Fig. 5. Impacts of traffic congestion in Khartoum

The economic impacts of the traffic congestion are measured through fuel wasted and time delay. The total delay in hours reached 30 on peak hours of weekdays in a month. During this time, 60 liters of fuel were used. In other words, one hour of traffic congestion cost the city a waste of 30 hours of productivity time and 60 liters of fuel. The gases released from cars contribute in harming the environment as well. Traffic congestion adds to this occurrence. The un-burnt hydrocarbon (HC); Carbon Monoxide (CO), Nitrogen Oxides (NO) were released in the atmosphere during that delay times. 


\section{REDUCING TRAFFIC CONGESTION IN KHARTOUM}

Khartoum, like most growing cities, faces the problem of traffic congestion resulting from a number of causes. It is essential to alleviate the problem by implementing effective measures and policies as outlined below.

Traffic congestion on roads can be reduced by either increasing road capacity or by reducing traffic demand. Road capacity can be increased in a number of ways such as adding more lanes, creating new roads, and improvements in traffic management. Reduction of demand can include, parking restrictions, and incentives to use public transport.

If citizens were offered an adequate and accessible public transport, they would economically be more incentivized to use it, instead of their cars. Recently, the government of the state initiated the founding of Private Parking. This project will improve the organization of the parking system in Khartoum by offering services of the latest technologies. The use of these services will be charged and the time will be limited hours per car for any vehicle. The collected revenues from this project will be spend to create new parking spaces, and underground garages. This project will significantly help in reducing traffic congestions in Khartoum.

For drivers who have to go through the city to reach their destination, the outer ring road will provide them an alternative option. Additionally, this ring road will be linked with the national highways.

Adopting Bus Rapid Transit (BRT) system would be more beneficial for Khartoum. The BRT are very effective in directly speeding up public transportation, and indirectly speeding up travel by car by getting car traffic off the roads.

Proper parking system will give the solution of random parking and parking congestion. Car parks should be created in market centers for private cars who wish to shop to use instead of parking by the roadside. There should be dedicated bus stops for public transport and taxis for picking up passengers.

Providing different lanes for different types of vehicles, bus lane should be marked on the roads. Financial penalties should be imposed to make the drivers maintain the lane discipline especially at traffic junctions and not to jump red lights and block the intersection, causing further traffic congestion. Also, pedestrian should be trained sufficiently to follow traffic rules and prevent them from certain congestion causing habits such as wrong and unsafe crossing of roads. This kind of implication of law can mitigate traffic jam in short run, but in long run, all the people should be involved to create awareness and responsibility to the society.

\section{CONCLUSION}

The research was undertaken to evaluate the main causes and adverse impacts of traffic congestion on most roads of Khartoum. Based on the study findings, the conclusion drawn as follows:

- The peak periods were found in the morning from 7a.m. to 9 a.m. while afternoon peak period between 2p.m. and 4p.m. Morning congestion when people go to work (47\%) exceeded afternoon congestion when people $(40 \%)$. The roads are completely free from congestion $(13 \%)$ during the remaining time of the day.

- Demand for transport is increasing due to increasing population working and/or living in Khartoum. Public transportation is a big issue due to insufficient number of buses operating in the city. Moreover, the lack of parking spaces incentivizes people stay longer on the road or park illegally.

- The key findings of the study are expansion of roads to increase capacity and adopting Bus Rapid Transit (BRT) system to improve public transport in Khartoum. The road capacity in Khartoum is low. Because of inadequate number of lanes, roads are too narrow to withstand transport requirements and ring roads are needed. The improvement of the public transport, providing adequate parking places with charging fees, if implemented, would have reduced road congestion. and will take time to implement.

- The study findings can be a useful tool for the government and the policy-makers in Sudan to reorient their strategies and plans to mitigate traffic congestion in the capital. 
- Alleviating traffic congestion still needs more research and practice. Additional researches could be extended toward different alternative modes of transportation to tackle the traffic congestion problem in Khartoum.

\section{REFERENCES}

[1] C. TILAK and R. R. REDDY, "Measurement of Traffic Congestion on High Dense Urban Corridors in Hyderabad City," Anveshana's Inter. Journal of research in Engineering and Applied Sciences, 1(10), 2016.

[2] W. ZHANG, "Managing Traffic Congestion Case Study of Hangzhou," European Spatial Planning and Regional Development, Blekinge Institute of Technology, 2011.

[3] A. M. RAO, and K. R. RAO, "Measuring Urban Traffic Congestion A Review," International Journal for Traffic and Transportation Engineering, 2(4), 286-305, 2012.

[4] S. B. Raheem, W. A. Olawoore, D. P. Olagunju, and E. M. Adeokun, "The Cause, Effect and Possible Solution to Traffic Congestion on Nigeria Road (A Case Study of Basorun - Akobo Road, Oyo State)," International Journal of Engineering Science Invention, 4(9), 10-14, 2015.

[5] FHWA-US Department of Transportation, Office Operations, Federal Highway Administration. A Study on Office of Traffic Operations, Retrieved December, 2015.

[6] S. Thakur and R. Singh, "A Review of Traffic Congestion Problem and Various Automated Traffic Measurement Sensors and Techniques," Indian Journal of Science and Technology, Vol. 9(47), December 2016.

[7] Transport Advisory Committee (TAC), Report on Study of Road Traffic congestion in Hong Kong, 2014.

[8] V. Jain, A. Sharma, and L. Subramanian, "Road Traffic Congestion in the Developing World, " Proceedings of the 2nd ACM Symposium on Computing for Development, 2012.

[9] T. Atomode, "Assessment of Traffic Delay Problems and Characteristics at Urban Road Intersections: A Case Study of Ilorin, Nigeria," IOSR-JHSS IOSR Journal of Humanities and Social Science, 12(4), 06-16, 2013.

[10] Harriet, T., Poku, K. and Anin, E. K., "Logistics Inefficiencies of Urban Transportation System in Ghana," International Journal of Humanities and Social Science, 3(6), 2013.

[11] R. B. Kiunsi, "A Review of Traffic Congestion in Dar es Salaam City from the Physical Planning Perspective," JSD Journal of Sustainable Development, 6(2), 2013.

[12] I. Doçi, and M. Bajraktari, "Stydying the Infulence of Heavy Tranportation Vehicles in Congested Urban Traffic Network Using Traffic Simulations," Scientific Proceedings Xix International Scientific-Technical Conference "Trans \& Motauto", Vol. 3, p 100-103, 2011.

[13]D. Schrank and T. Lomax, The 2007 Urban Mobility Report, Texas Transportation Institute, The Texas A\&M University System, P 138, September 2007

[14] L. James and D. Nahl, Road Rage and Aggressive Driving: Steering Clear of Highway Warfare, Prometheus; No Edition Stated edition, P 298, Oct. 2000.

[15] World Health Organization (WHO), "Traffic Problem in Big Cities," 2012. [Online]. URL:http://www.scholaradvisor.com/ essayexamples/effect-essay-traffic-problems-of-big-city/.

[16] A. D. Elisonguo, "The Social-Economic Impact of Road Traffic Congestion in Dar Es Salaam Region," doctoral dissertation, Mzumbe University, 2013.

[17] G. J. Roth, "An Economic Approach to Traffic Congestion," The Town Planning Review, 36(1), 49-61, 1965.
[18]R. Robinson, "Problems in the urban environment: Traffic congestion and its effects", Retrieved November 29, 2015.

[19] J. Currie, and R. Walker, "Traffic Congestion and Infant Health: Evidence from E-Z Pass," American Economic Journal: Applied Economics, 3(1), 65-90, 2011.

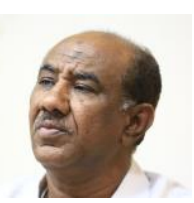

Dr. Magdi Zumrawi was born in Omdurman, Sudan, 19 May 1963. He received the B.Sc. degree in Civil Engineering and M.Sc. degree in Road Technology from University of Khartoum in 1987 and 1991, respectively. He achieved Ph.D. in Highway and Railway Engineering in Sept. 2000, Chang'An University, Xi'an, China. Now he is Associate Professor in Highway Engineering. His present occupation is Deputy Dean for Academic Affairs, Faculty of Eng., Khartoum University, since Dec. 2019. He is a highway expert working with local and international consultant firms. He has published many articles in local and international journals and attended national and international conferences. He is a member of International Society for Soil Mechanics and Geotechnical Engineering. He is a senior member of the APCBEES. 